\title{
Perancangan Prototipe Mobile User Experience Aplikasi Peningkatan Sumber Daya Desa Menggunakan Metode Double Diamond
}

\section{Designing a Mobile User Experience Prototype for Village Resources Improvement Application Using the Double Diamond Method}

\author{
AGIL CAHYO PRIYANTONO ${ }^{1 *}$, FIRMAN ARDIANSYAH $^{1}$
}

\begin{abstract}
Abstrak
Jumlah penduduk Indonesia mencapai 262 juta jiwa dan memiliki lebih dari 30 ribu pulau, namun sebanyak 122 kabupaten Indonesia dikategorikan sebagai daerah tertinggal. Hal tersebut dikarenakan kurangnya pemanfaatan sumber daya desa oleh masyarakat setempat. Salah satu cara memaksimalkan sumber daya desa adalah dengan membantu masyrakat luar untuk memberikan gagasan ide serta penggalangan dana ke desa. Oleh karena itu dibutuhkan suatu sarana yang menghubungkan perangkat desa dengan masyarakat luar. Tujuan penelitian ini adalah pembuatan prototipe mobile user experience aplikasi pembangunan desa, serta mengevaluasi usability dari prototipe tersebut. Metode yang digunakan pada penelitian ini adalah Double Diamond, dengan pengujian usability menggunakan metode think aloud kepada responden yang memenuhi kriteria. Hasil yang didapatkan dari penelitian yang dilakukan adalah prototipe mobile apps sampai tahap medium fidelity dengan pengujian menggunakan think aloud usability learnability menghasilkan success rate $91.7 \%$ dan usability satisfaction menghasilkan nilai rata-rata kepuasan sebesar 92.5\%. Secara keseluruhan, pengguna dapat menggunakan prototipe aplikasi peningkatan sumber daya desa dengan mudah dan benar.
\end{abstract}

Kata Kunci: double diamond, experience, prototipe, sarana, sumber daya, think aloud.

\begin{abstract}
Indonesia's population reaches 262 million and has more than 30 thousand islands, but as many as 122 Indonesian districts are categorized as underdeveloped regions. This is due to the lack of utilization of village resources by the local community. One way to maximize village resources is to help outside communities to provide ideas and raise funds to the village. Therefore we need a facility that connects village officials with outside communities. The purpose of this study is to make a prototype of a mobile user experience for village development applications, and to evaluate the usability of the prototype. The method used in this study is Double Diamond, with usability testing with a think aloud method for respondents who meet the criteria. The results obtained from the research conducted are prototype mobile apps until the medium fidelity testing stage by using think aloud usability learnability to produce $91.7 \%$ success rates and usability satisfaction to produce an average value of satisfaction of 6.7. Overall, users can use the prototype application to increase village resources easily and correctly.
\end{abstract}

Keywords: double diamond, experience, facilities, prototype, resources, think aloud.

\section{PENDAHULUAN}

Indonesia merupakan sebuah negara kepulauan dengan dua pertiga luas lautan lebih besar dari luas daratan. Menurut Badan Pusat Statistika (BPS) pada tahun 2017, jumlah penduduk Indonesia mencapai 262 juta jiwa dan memiliki kurang lebih tiga puluh ribu pulau di Indonesia. Kementrian Desa, Pembangunan Daerah Tertinggal, dan Transmigrasi (KDPDTT) menyatakan, Indonesia telah melalui urbanisasi yang pesat sejak tahun 1970 dengan 45\% dari

\footnotetext{
${ }^{1}$ Departemen Ilmu Komputer, Fakultas Matematika dan Ilmu Pengetahuan Alam, Institut Pertanian Bogor, Dramaga, Bogor 16680 ;

*Penulis Korespondensi: Surel: agil_cp@apps.ipb.ac.id
} 
populasi atau 119 juta jiwa penduduk hidup di daerah pedesaan, namun sebanyak 122 kabupaten di wilayah Indonesia masih dikategorikan sebagai daerah tertinggal.

Tingkat kemiskinan jauh lebih tinggi di daerah pedesaan serta orang pedesaan sangat rentan untuk kembali jatuh dalam kemiskinan. Keluarga yang tertinggal di daerah pedesaan juga cenderung mengalami ketertinggalan terkait beberapa indikator pembangunan manusia. Di daerah pedesaan, terdapat $86 \%$ kelahiran bayi yang ditangani oleh tenaga ahli dan $62 \%$ memiliki akses memiliki air minum yang aman. Secara keseluruhan pedesaan Indonesia rentan terhadap kemiskinan yang merupakan faktor penting pertumbungan Indonesia di masa depan.

Ekonomi digital Indonesia yang dinamis, sebagian didorong oleh populasi generasi muda yang paham dengan teknologi, bersamaan dengan adanya investasi infrastruktur dalam memberikan akses untuk menjembatani antara masyarakat luar desa dengan perangkat desa. Peranan masyarakat luar dapat berkontribusi dalam membangun desa melalui gagasan ide keratif yang ditawarkan untuk menangani permasalahan desa.

Dalam upaya mempertemukan pihak yang berkaitan, diperlukan sebuah fasilitas untuk menjembatani antara masyarakat luar dengan perangkat desa yang sesuai untuk membangun desa. Hal tersebut untuk menyampaikan informasi permasalahan desa yang tengah dialami saat ini. Kontribusi yang dilakukan oleh masyarakat luar dapat berupa gagasan ide sebagai solusi untuk desa yang dituju, nantinya ide tersebut akan dijadikan proyek untuk pembangunan desa. Selain itu, masyarakat umum atau investor yang ingin berkontribusi dalam pembangunan desa dapat memberikan bantuan berupa dana untuk pelaksanaan proyek yang telah ditentukan desa tersebut.

Penelitian ini merancangan prototipe aplikasi I-Kud, yaitu aplikasi pembangunan desa yang diharapkan dapat meningkatkan sumber daya desa di Indonesia. Perancangan aplikasi ini dibuat berdasarkan user experience dengan pengujian usability sehingga aplikasi ini dapat digunakan dengan nyaman dan tepat guna.

\section{METODE}

\section{Data Penelitian}

Data yang digunakan pada penelitian ini adalah data wawancara yang dilakukan menggunakan purposive sampling, dimana teknik ini memilih tiga responden dengan tujuan yang ditetapkan oleh peneliti. Kriteria responden yang ditentukan peneliti adalah mahasiswa Institut Pertanian Bogor dengan kriteria telah melakukan survei ke desa-desa dan melakukan kontak langsung terhadap perangkat desa lebih dari sepuluh kali. Ketiga responden berasal dari departemen yang berbeda yaitu Sains Komunikasi Pengembangan Masyarakat, Ekonomi Sumberdaya Lingkungan, dan Ilmu Komputer.

\section{Tahapan Penelitian}

Perancangan prototipe ini dilakukan dengan menggunakan metode Double Diamond. Metode ini memberikan kebebasan desainer dari batasan yang tidak diperlukan dan mengevaluasi suatu desain yang sudah ada, hal ini bertujuan untuk mengetahui kelemahan dan kelebihan desain untuk diperbaiki sehingga cocok digunakan.

Menurut Norman (2013), metode ini dibagi menjadi 4 tahap, yaitu discover dan define untuk menemukan masalah yang tepat, lalu develop dan deliver untuk menemukan solusi yang benar. Keempat tahap tersebut akan membentuk pola divergen dan konvergen berganda yang pertama kali dikenalkan oleh British Design Council pada tahun 2005 seperti Gambar 1. 


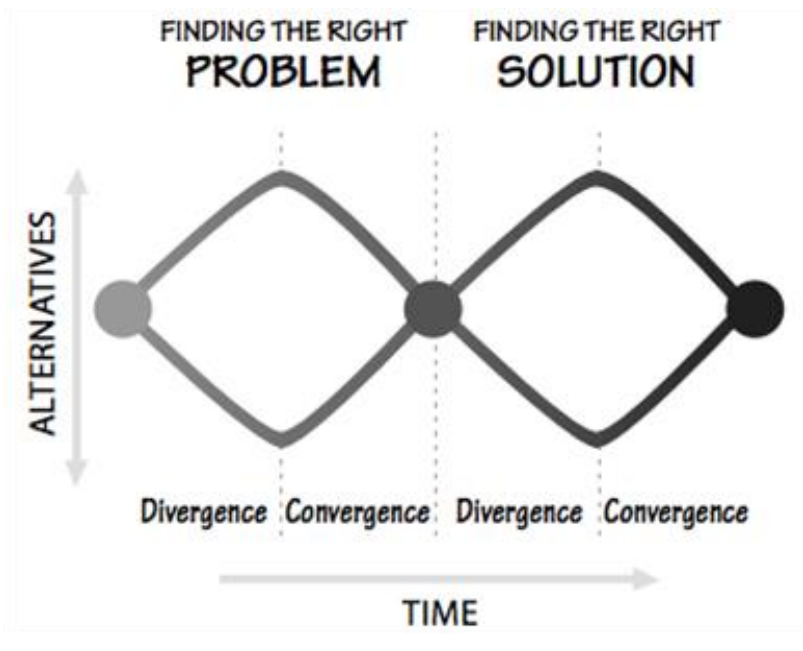

Gambar 1 Tahapan metode double diamond (Norman 2013).

\section{Discover}

Pada tahapan ini, peneliti mengumpulkan informasi dengan cara melakukan pengamatan kepada calon pengguna untuk mendapatkan insight sebanyak-banyaknya dari calon pengguna. Pengamatan yang dilakukan berupa wawancara kepada responden, kemudian informasi yang didapatkan direpresentasikan ke dalam bentuk visual seperti empathy map dan user journey mapping.

\section{Define}

Pada tahapan ini, peneliti menganalisis informasi yang didapatkan pada tahapan sebelumnya. Informasi tersebut kemudian dipersempit untuk menentukan permasalahan yang akan diselesaikan. Analisis yang dilakukan ialah dengan cara membandingkan catatan, memahami dan mengelola persepsi para responden, serta mengidentifikasi ide yang paling efektif yang kemudian dirangkum ke dalam user persona dan sticky note berupa poin kesulitan (pain) dan poin keinginan (gain).

\section{Develop}

Pada tahapan ini, peneliti berfokus pada perancangan ide dan solusi dengan cara melakukan brainstorming. Ide tersebut dirancang ke dalam bentuk alur navigasi, nantinya rancangan tersebut menjadi acuan desain berbentuk low fidelity dan medium fidelity kemudian diimplementasikan ke dalam bentuk prototipe.

\section{Deliver}

Pada tahapan deliver, peneliti mulai berfikir secara konvergen, fokus pada apa yang dapat diberikan pada responden. Hal ini dilakukan dengan usability testing prototipe kepada responden untuk memastikan desain prototipe terhadap standar serta peraturan berhasil mengatasi masalah dan mengetahui tingkat kegunaan aplikasi. Usability testing akan dilakukan menggunakan metode think aloud (Galitz 2007).

Alat ukur pengujian usability objective yang dilakukan dari aplikasi ini menggunakan metode yang telah digunakan oleh Galitz (2007), dua komponen penilaian usability, yaitu learnability: seberapa mudah bagi pengguna untuk menyelesaikan tugas-tugas dan satisfaction: seberapa menyenangkan menggunakan tampilan yang disediakan.

Dalam pengujian learnability responden akan diberikan task terkait aplikasi I-Kud untuk menentukan nilai kepuasan penggunaan aplikasi I-Kud, responden diberikan pengujian terhadap 8 task yang telah ditentukan seperti pada Tabel 1. 
Tabel 1 Daftar task untuk usability testing yang telah ditentukan

\begin{tabular}{ll}
\hline Kode tugas & \\
\hline T1 & Masuk aplikasi sebagai personal menggunakan akun Google \\
T2 & Melakukan sayembara ide di wilayah Bogor dengan kategori pariwisata di desa \\
& Sukamaju \\
T3 & Melakukan penggalangan dana di rekomendasi 'penggalangan dana' di desa Likaliku \\
T4 & Melakukan pencarian desa Sukamaju, lalu 'ikuti' dan beri pesan ke desa tersebut \\
T5 & Melihat notifikasi yang masuk, buka notifikasi yang baru masuk \\
T6 & Memuka halaman proyek, jelajahi riwayat proyek yang sudah dijalani \\
T7 & Membuka halaman pesan, balas pesan yang belum terbaca \\
T8 & Membuka halaman profil, melihat daftar sayembara yang disimpan dan desa yang \\
& diikuti
\end{tabular}

Dalam pengujian satisfaction, responden akan diberikan kuesioner terkait aplikasi I-Kud untuk menentukan nilai kepuasan penggunaan aplikasi I-Kud. Untuk kuesioner akan diberikan 19 elemen Computer System Usabilty Questionnaire (CSUQ), pada masing-masing elemen terdapat tujuh alternatif jawaban kuesioner yaitu tidak setuju (1) sampai sangat setuju (7) (Tullis 2013). Daftar pertanyaan kuesioner dapat dilihat pada Tabel 2.

Tabel 2 Daftar pertanyaan kuesioner nilai kepusaan pengguna aplikasi I-Kud

\begin{tabular}{ll}
\hline No & \multicolumn{1}{c}{ Elemen } \\
\hline 1 & Secara keseluruhan, saya puas dengan betapa mudahnya menggunakan sistem ini \\
2 & Mudah untuk menggunakan sistem ini \\
3 & Saya dapat secara efektif menyelesaikan tugas dan skenario menggunakan sistem ini \\
4 & Saya dapat menyelesaikan tugas dan skenario dengan cepat menggunakan sistem ini \\
5 & Saya dapat secara efisien melakukan tugas dan skenario dengan cepat menggunakan sistem ini \\
6 & Saya merasa nyaman menggunakan sytem ini \\
7 & Mudah untuk belajar menggunakan sistem ini \\
8 & Saya percaya saya bisa menjadi produktif dengan cepat menggunakan sistem ini \\
9 & Sistem memberikan pesan kesalahan yang dengan jelas memberi tahu saya cara memperbaiki masalah \\
10 & Setiap kali saya membuat kesalahan dengan menggunakan sistem, saya dapat memulihkan dengan \\
11 & mudah dan cepat \\
12 & Informasi (pesan di layar) yang disediakan dengan sistem ini jelas \\
13 & Informasi yang disediakan untuk sistem mudah dimengerti \\
14 & Informasi itu efektif dalam membantu saya menyelesaikan tugas dan skenario \\
15 & Organisasi pada layar sistem ini jelas \\
16 & Antarmuka sistem ini sangat menyenangkan \\
17 & Saya suka menggunakan antarmuka sistem ini \\
18 & Sistem ini mempunyai fungsi dan kemampuan yang saya harapkan \\
19 & Keseluruhan, saya puas dengan sistem ini \\
\hline
\end{tabular}

Dari hasil pengujian usability tersebut, peneliti akan mendapatkan rekomendasi perbaikan yang diperoleh dari responden. Rekomendasi perbaikan akan menjadi acuan dalam pengembangan aplikasi pada tahap berikutnya.

\section{HASIL DAN PEMBAHASAN}

\section{Discover}

Pada tahapan ini peneliti melakukan survei terhadap seluruh ormawa Institut Pertanian Bogor dan mendapatkan tiga orang mahasiswa yang sudah sering melakukan kegiatan survei desa dan melakukan komunikasi dengan perangkat desa. Setelah itu peneliti melakukan wawancara terhadap responden terkait kebiasaan mereka dalam melakukan kegiatan 
pembangunan desa. Dari data wawancara, dapat direpresentasikan dalam bentuk empathy map seperti pada Gambar 2.

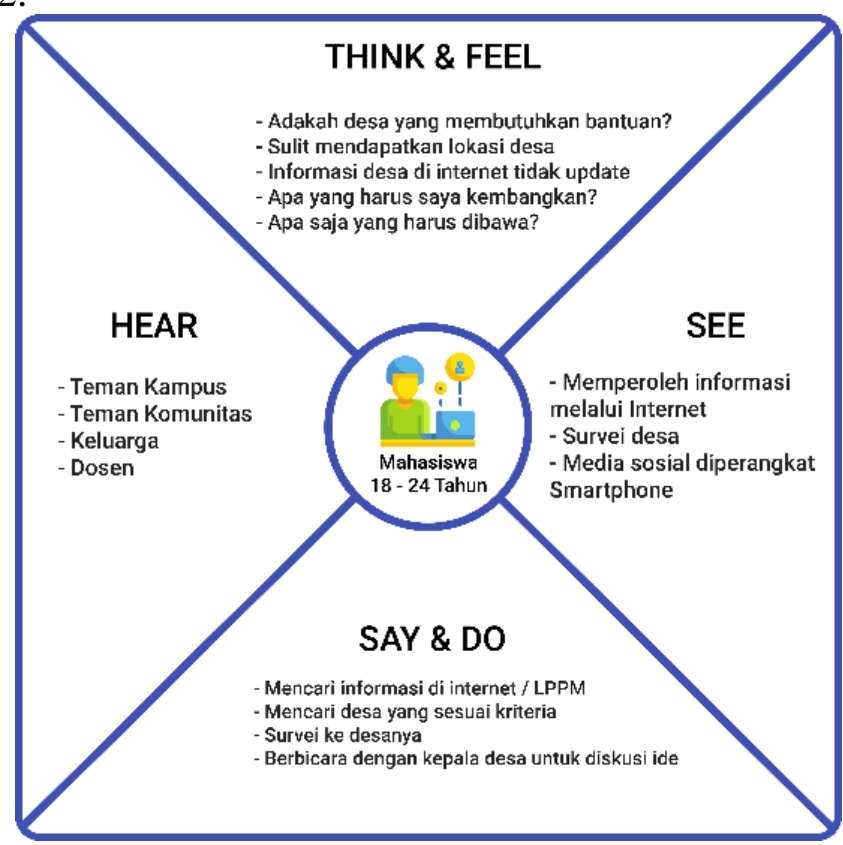

Gambar 2 Empathy map I-Kud.

Kemudian dari hasil wawancara tersebut, peneliti menggambarkan siklus kegiatan target pengguna yang direpresentasikan dalam user journey seperti pada Gambar 3.

\section{User Journey Map - I-Kud}

Goals - Mendapatkan pengalaman baik dalam menyalurkan gagasan kepada desa

\begin{tabular}{|c|c|c|c|c|c|}
\hline Stages & Search \& Find & Want to Go & At Village & Waiting & - Get the Answare \\
\hline Actions & $\begin{array}{l}\text { - Mencari desa yang sesuai } \\
\text { dengan kriteria } \\
\text { - Mencari informasi desa lewat } \\
\text { internet }\end{array}$ & $\begin{array}{l}\text { Mencari informasi kondisi desa } \\
\text { Memeriksa perlengkapan pergi } \\
\text { Mencari rute perjalanan }\end{array}$ & $\begin{array}{l}\text { Memberitahu tujuan } \\
\text { kedatangan ke desa } \\
\text { Melihat kondisi sumber } \\
\text { daya desa } \\
\text { Memberikan gagasan } \\
\text { kepada perangkat desa }\end{array}$ & $\begin{array}{l}\text { Menunggu jawaban dari } \\
\text { perangkat desa atas } \\
\text { gagasan yang ditawar- } \\
\text { kan }\end{array}$ & $\begin{array}{l}\text { Mendapatkan jawaban } \\
\text { atas gagasan yang } \\
\text { disampaikan }\end{array}$ \\
\hline \multicolumn{6}{|l|}{ Touch Points } \\
\hline Thoughts & $\begin{array}{l}\text { Saya harus menemukan desa } \\
\text { yang memiliki potensi sumber } \\
\text { daya yang cocok dengan } \\
\text { gagasan saya }\end{array}$ & $\begin{array}{l}\text { Saya butuh informasi keadaan } \\
\text { desa } \\
\text { Apakah perlengkapan saya } \\
\text { sudah lengkap? }\end{array}$ & $\begin{array}{l}\text { Saya ingin membahas } \\
\text { gagasan ide saya } \\
\text { dengan kepala desa }\end{array}$ & $\begin{array}{l}\text { Saya ingin kepastian } \\
\text { gagasan saya akan } \\
\text { dilakukan atau tidak }\end{array}$ & $\begin{array}{l}\text { Mermberi arahan } \\
\text { terhadap perangkat desa } \\
\text { terkait gagasan saya } \\
\text { yang }\end{array}$ \\
\hline Pain Points & $\begin{array}{l}\text { Informasi yang tersedia di } \\
\text { Internet tidak diperbaharui } \\
\text { Sedikit desa yang bisa } \\
\text { ditemukan di situs-situs } \\
\text { Internet }\end{array}$ & & $\begin{array}{l}\text { Kondisi desa yang } \\
\text { ternyata tidak sesuai } \\
\text { ekspetasi } \\
\text { Tidak tahu harus ber- } \\
\text { buat apa saja }\end{array}$ & $\begin{array}{l}\text { Perangkat desa yang } \\
\text { tidak kunjung memberi } \\
\text { kepastian }\end{array}$ & \\
\hline Feeling & $\stackrel{\circ}{\circ}$ & $\stackrel{\bullet}{\bullet}$ & $\bigodot_{\text {Frustasi }}^{\bullet}$ & $\stackrel{\bigcirc}{B}$ & $\underset{\text { Antusias }}{\bullet}$ \\
\hline
\end{tabular}

Gambar 3 User journey I-Kud.

\section{Define}

Pada tahap ini dilakukan penentuan responden, mengumpulkan informasi tentang kebutuhan pengguna nyata, pemahaman serta empati dari pengalaman pengguna. Hasil dari tahapan ini berupa user persona sebagai rangkuman dari informasi responden. Berdasarkan 
hasil wawancara, maka dibuatnya user persona mahasiswa Novan yang berusia 22 tahun. User persona tersebut dapat dilihat pada Gambar 4.

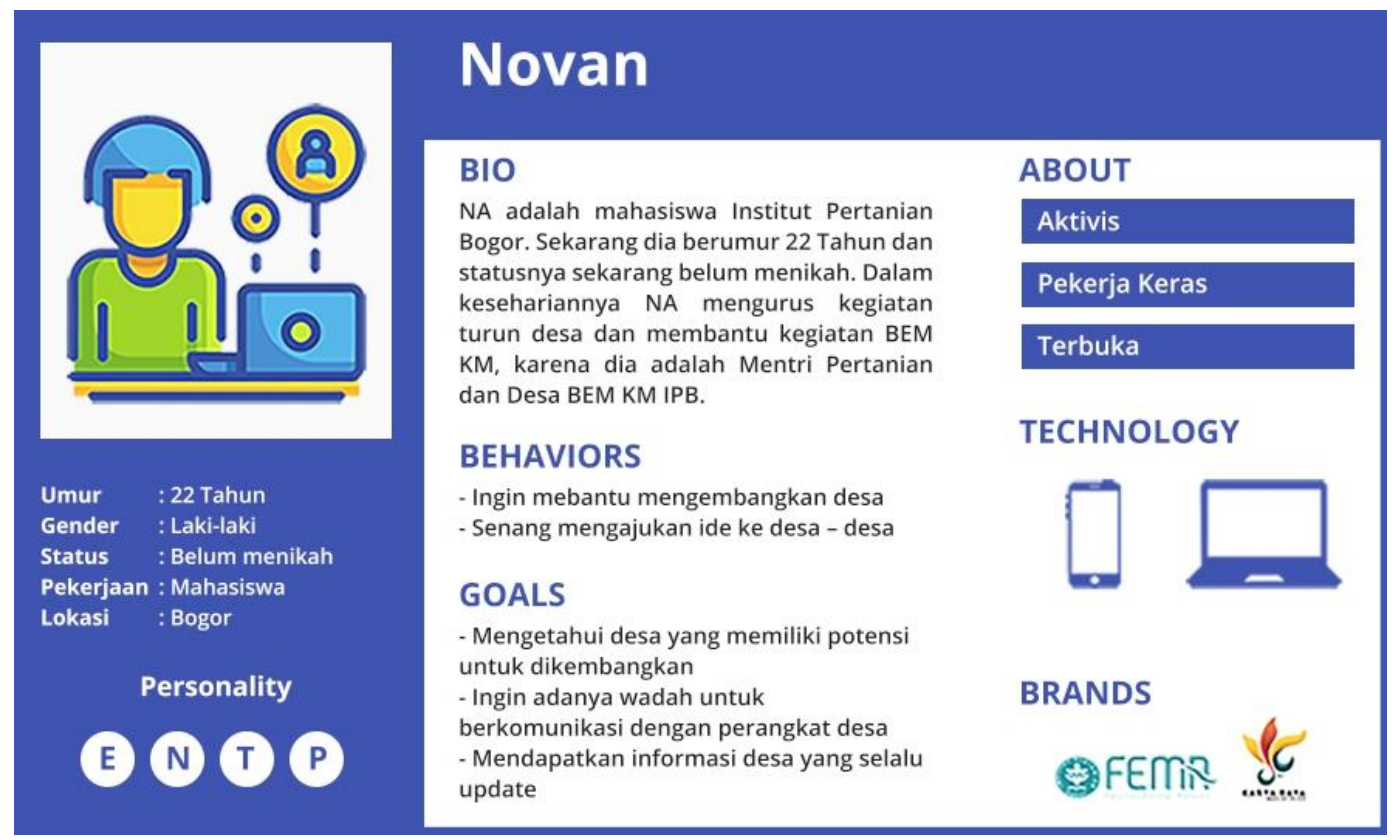

Gambar 4 User persona I-Kud.

Kemudian dari user persona tersebut, peneliti menggambarkan siklus berupa poin kesulitan (pain) dan poin keinginan (gain) yang direpresentasikan seperti pada Gambar 5.

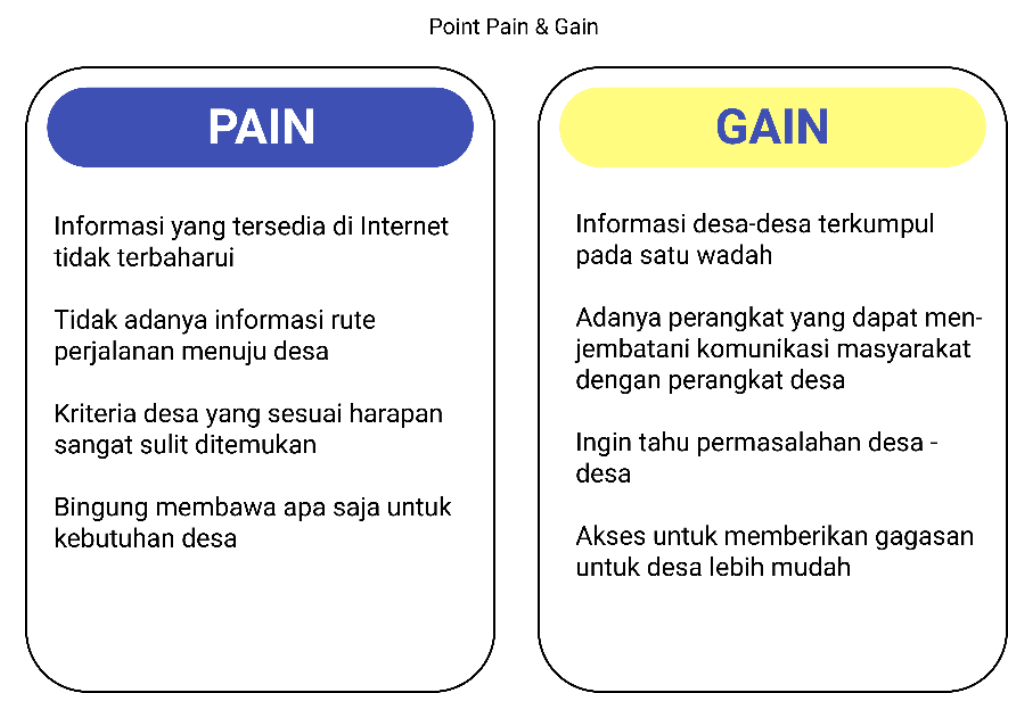

Gambar 5 Poin kesulitan (pain) dan poin keinginan (gain) I-Kud.

\section{Develop}

Pada tahapan ini, peneliti berfokus pada perancangan ide dan solusi dari kebutuhan responden dengan cara melakukan brainstorming. Ide tersebut dirancang ke dalam bentuk alur navigasi. Alur navigasi produk dibuat dalam bentuk flowchart untuk memudahkan dalam pembuatan prototipe aplikasi. Brainstroming dilakukan berdasarkan hasil dari user journey yang akan menghasilkan alur interaksi. Dari hasil alur interaksi tersebut akan menghasilkan diagram navigasi yang menampilkan fitur-fitur yang seharusnya ada dalam aplikasi. Gambar alur navigasi produk dapat dilihat pada Gambar 6.

Selanjutnya peneliti membuat wireframe sebagai rancangan kasar tampilan aplikasi dan dikembangkan lebih detail menjadi produk prototipe medium fidelity dengan menggunakan aplikasi Sketch App. Alur navigasi sudah menunjukan interaksi interface, sehingga prototipe 
ini membuat pengguna merasakan experience ketika menggunakannya. Setiap elemen perancangan pada tahap ini dilakukan berdasarkan data yang didapatkan pada proses sebelumnya. Potongan desain interface bagian onboarding prototipe aplikasi dapat dilihat pada Gambar 7 dan potongan desain interface aplikasi dapat dilihat pada Gambar 8 .

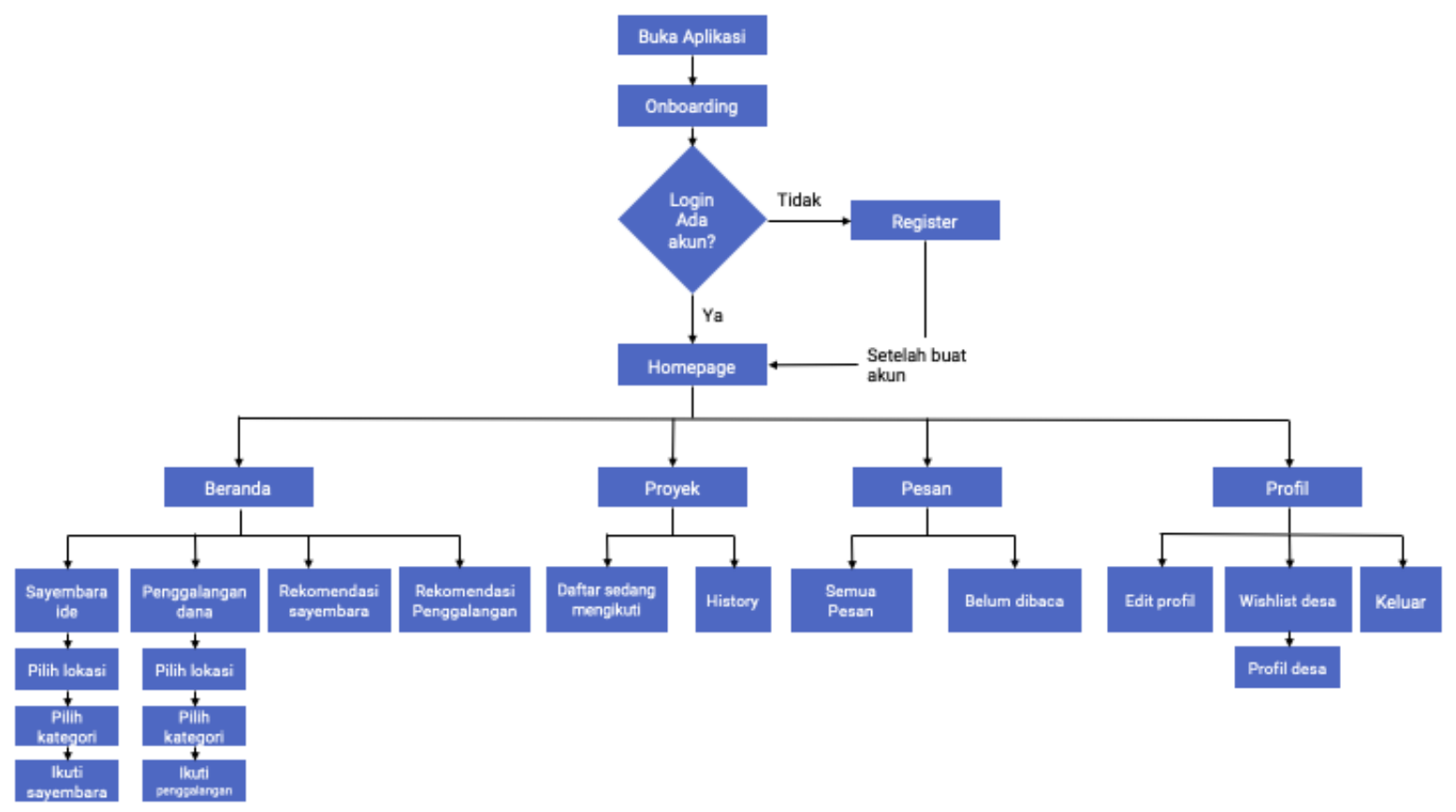

Gambar 6 Alur navigasi aplikasi
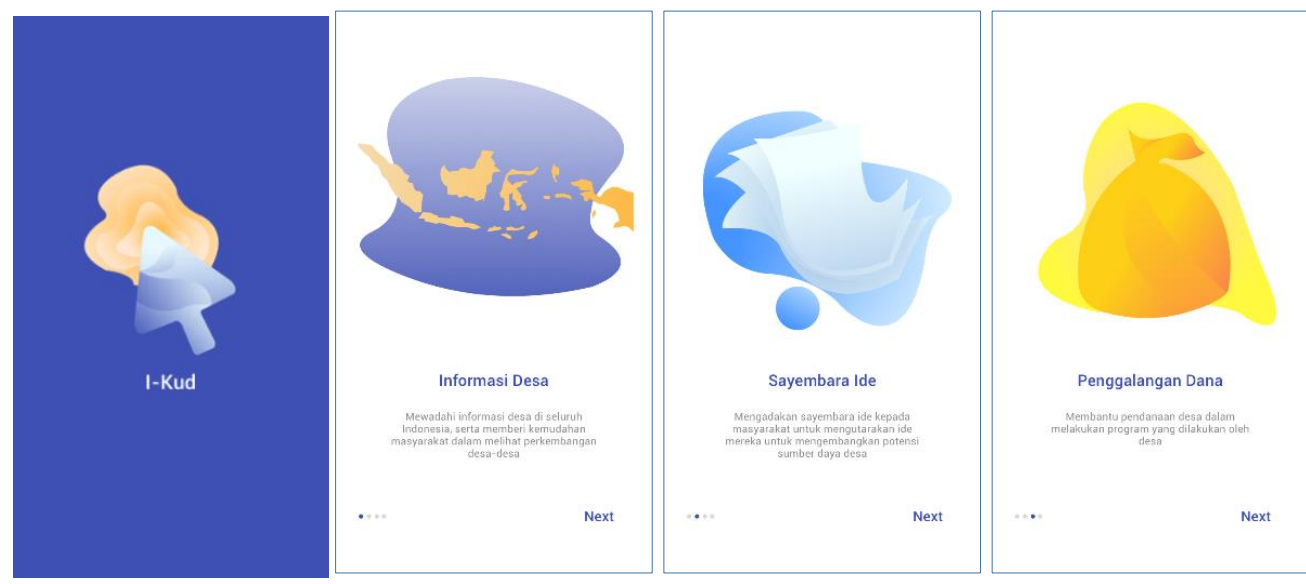

Gambar 7 Potongan interface prototipe bagian onboarding I-Kud.
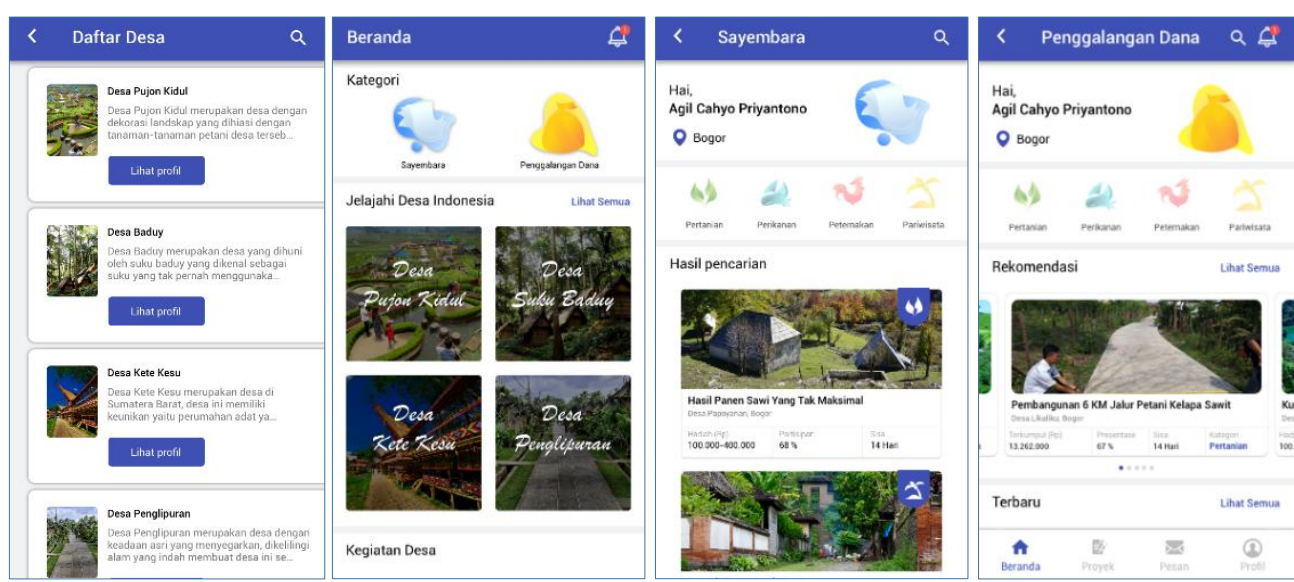

Gambar 8 Potongan interface prototipe halaman I-Kud 


\section{Deliver}

Pada tahap deliver, metode yang digunakan adalah usability testing dengan cara memberikan task penggunaan yang kemudian diujikan dengan memberikan gadget dengan prototipe aplikasi kepada responden. Responden yang terlibat dalam tahap deliver adalah responden 1, responden 2, responden 3. Ketiganya adalah responden yang ditetapkan dengan kriteria yang sesuai. Hasil pengerjaan task dalam pengujian learnability dapat dilihat pada Tabel 3 dan hasil pengujian satisfaction dengan kuesioner dapat dilihat pada Tabel 4. Nilai 1 menunjukkan task berhasil dilakukan, sementara nilai 0 menunjukkan task yang gagal dilakukan oleh responden.

Tabel 3 Hasil usability testing pengujian learnability

\begin{tabular}{lrrrrrrrrr}
\hline Responden & \multicolumn{1}{c}{ Kode task } & \multirow{2}{*}{ Total } \\
\hline R1 & T1 & T2 & T3 & T4 & T5 & T6 & T7 & T8 & \\
R2 & 1 & 0 & 1 & 1 & 1 & 1 & 1 & 1 & 7 \\
R3 & 1 & 1 & 1 & 1 & 1 & 0 & 1 & 1 & 7 \\
\hline Total & 1 & 1 & 1 & 1 & 1 & 1 & 1 & 1 & 8 \\
\hline
\end{tabular}

Dari total 24 task yang dilakukan, 2 task dinyatakan gagal karena responden tidak mengetahui makna ikon menu sayembara dan simbol tombol riwayat pada menu proyek. Kegagalan tersebut disebabkan oleh ketidakjelasan simbol tombol karena responden tidak mengetahui bahwa simbol yang tertera adalah tombol ke halaman tersebut. Hal ini memberikan success rate sebesar $91.7 \%$, yang berarti responden merasa mudah dalam menggunakan prototipe aplikasi I-Kud.

Tabel 4 Hasil usability testing pengujian satisfaction

\begin{tabular}{|c|c|c|c|c|c|}
\hline \multirow{2}{*}{ No } & \multirow{2}{*}{ Elemen } & \multicolumn{3}{|c|}{ Responden } & \multirow{2}{*}{ Rataan } \\
\hline & & 1 & 2 & 3 & \\
\hline 1 & $\begin{array}{l}\text { Secara keseluruhan, saya puas dengan betapa mudahnya menggunakan sistem } \\
\text { ini }\end{array}$ & 7 & 7 & 6 & 6.7 \\
\hline 2 & Mudah untuk menggunakan sistem ini & 7 & 7 & 7 & 7 \\
\hline 3 & $\begin{array}{l}\text { Saya dapat secara efektif menyelesaikan tugas dan skenario menggunakan } \\
\text { sistem ini }\end{array}$ & 7 & 7 & 7 & 7 \\
\hline 4 & $\begin{array}{l}\text { Saya dapat menyelesaikan tugas dan skenario dengan cepat menggunakan } \\
\text { sistem ini }\end{array}$ & 7 & 7 & 7 & 7 \\
\hline 5 & $\begin{array}{l}\text { Saya dapat secara efisien melakukan tugas dan skenario dengan cepat } \\
\text { menggunakan sistem ini }\end{array}$ & 7 & 7 & 7 & 7 \\
\hline 6 & Saya merasa nyaman menggunakan sytem ini & 6 & 6 & 6 & 6 \\
\hline 7 & Mudah untuk belajar menggunakan sistem ini & 7 & 7 & 7 & 7 \\
\hline 8 & $\begin{array}{l}\text { Saya percaya saya bisa menjadi produktif dengan cepat menggunakan sistem } \\
\text { ini }\end{array}$ & 6 & 6 & 6 & 6 \\
\hline 9 & $\begin{array}{l}\text { Sistem memberikan pesan kesalahan yang dengan jelas memberi tahu saya cara } \\
\text { memperbaiki masalah }\end{array}$ & 5 & 6 & 6 & 5.7 \\
\hline 10 & $\begin{array}{l}\text { Setiap kali saya membuat kesalahan dengan menggunakan sistem, saya dapat } \\
\text { memulihkan dengan mudah dan cepat }\end{array}$ & 7 & 7 & 7 & 7 \\
\hline 11 & Informasi (pesan di layar) yang disediakan dengan sistem ini jelas & 7 & 5 & 5 & 5.7 \\
\hline 12 & $\begin{array}{l}\text { Sistem ini memberikan kemudahan untuk menemukan informasi yang saya } \\
\text { butuhkan }\end{array}$ & 6 & 6 & 6 & 6 \\
\hline 13 & Informasi yang disediakan untuk sistem mudah dimengerti & 7 & 7 & 6 & 6.7 \\
\hline 14 & Informasi itu efektif dalam membantu saya menyelesaikan tugas dan skenario & 5 & 6 & 6 & 5.7 \\
\hline 15 & Organisasi pada layar sistem ini jelas & 7 & 7 & 7 & 7 \\
\hline 16 & Antarmuka sistem ini sangat menyenangkan & 7 & 7 & 6 & 6.7 \\
\hline 17 & Saya suka menggunakan antarmuka sistem ini & 7 & 7 & 7 & 7 \\
\hline 18 & Sistem ini mempunyai fungsi dan kemampuan yang saya harapkan & 6 & 7 & 6 & 6.3 \\
\hline 19 & Keseluruhan, saya puas dengan sistem ini & 7 & 6 & 6 & 6.3 \\
\hline Total & & 125 & 125 & 121 & 6.5 \\
\hline
\end{tabular}


Dari total 57 elemen kepuasan dalam kuesioner nilai kepuasan responden ialah 6.5 dari 7 $(92.5 \%)$. Hal ini membuktikan responden merasa senang menggunakan prototipe aplikasi IKud.

Untuk memvalidasi asumsi peneliti pada tahap deliver, peneliti menanyakan langsung kepada responden terkait pain points yang ditemui saat usability testing. Hasilnya antara lain:

- Dari ketiga responden, tidak ada yang merasa kesulitan dalam mencari dan mendapatkan informasi yang ada di prototipe. Menurut mereka, tidak sulit untuk melihat informasi yang disajikan, namun ukuran font yang tertera pada tampilan sayembara dan penggalangan dana masih terlalu kecil.

- Salah satu responden sangat menyukai tampilan yang diberikan, responden sangat suka dengan logo yang terlihat jelas dan besar.

- Menurut responden, aplikasi ini sangat membantu mereka menemukan desa yang berada di suatu daerah dengan mudah.

\section{SIMPULAN}

Perancangan prototipe aplikasi peningkatan sumber daya desa (I-Kud) dibuat hingga tahap medium-fidelity dengan memperhatikan aspek user experience dan telah diujikan kepada tiga responden mahasiswa Institut Pertanian Bogor dengan kriteria melakukan survei dan melakukan kontak langsung terhadap desa lebih dari sepuluh kali. Hasil pengujian kepada mahasiwa Institut Pertanian Bogor diperoleh success rate learnability sebesar $91.7 \%$ dan success rate satisfaction sebesar $92.5 \%$. Success rate menunjukan tingkat kemudahan pengguna dalam menggunakan prototipe peningkatan sumber daya desa bagi masyarakat luar desa. Dapat disimpulkan secara keseluruhan bahwa pengguna dapat menggunakan prototipe aplikasi peningkatan sumber daya desa dengan mudah dan benar.

\section{DAFTAR PUSTAKA}

[BPS] Badan Pusat Statistik. 2018. Data kependudukan Indonesia [Internet]. [diunduh 2018 Nov 9] https://www.bps.go.id/.

Galitz, Wilbert O. 2007. The Essential Guide to User Interface Design: An Introduction to GUI Design Principles and Techniques. Canada (CA): Wiley Publish-ing, Inc.

[KDPDTT] Kementrian Desa, Pembangunan Daerah Tertinggal, dan Transmigrasi. 2019. Profil daerah tertinggal [Internet]. [diunduh 2019 Apr 16] http://datin.kemendesa.go.id/simpor a/report_tertinggal_provsmry.php.

Norman D. 2013. The Design of Everyday Things (Revised \& Expanded Version). New York (US): Basic Books.

Tullis T, Albert B. 2013. Measuring the User Experience Collecting, Analyzing, and Presenting Usability Metrics Ed. ke-2. Walham (USA): Elsevier. 